\title{
Restoration mortars at IRT: optical and hygroscopic properties of surfaces
}

\author{
by N.Ludwig*, E. Rosina** \\ * IFGA, University of study of Milan, Milan, Italy, \\ ** BEST Dept., Polythecnic of Milan, Milan, Italy,
}

\begin{abstract}
Plaster finishing affects thermal and hygroscopical behaviour of the exterior layers of material. IRT application, active and passive approaches, is useful to localize plasters which were superimposed by means of different tools (float, sponge, trowel, spatula). Laboratory tests on plaster samples allowed to
\end{abstract}

\section{Introduction}

IR Thermography usefully integrates the visual inspection and the videomicroscopy in the field. Microscopy allows to recognise the texture of the surfaces and their state of conservation. Texture of the material affects the distribution of surface temperature [1], especially at transient condition. Moreover, the roughness of surface and density of the exterior layers (few $\mathrm{mm}$ ) have some influence on the absorbance.

The research starts from the observation in the field of the hygroscopic behaviour of different textures of mortars [2] at high $\mathrm{RH}$ rate and low ambient temperature: textures, those were obtained using hard tools (e.g. spatula, wooden float, trowel), have harder surfaces, more compacted, which facilitate the condensation of water vapour; soft tools finishing (sponge, sponge float) have a rough surface, which facilitate the absorption and evaporation of moisture. In case of contiguity between two different finishing, the edges of rougher surface (around more compact texture) show major damage.

In restoration of plasters and mortars, the operators use both kinds of instruments, only dependently on the extension of the "patch" and the final aesthetic effect.

Early detection of these risk areas, by use of IRT, is a great deal for preservation of historical buildings without a controlled HACV system, and an advancement for the restoration techniques of precious surfaces.

For that, authors studied the surfaces properties of responding to thermal stimulation and humidity exchange between surfaces and ambient, by means of NDT as IRT. 


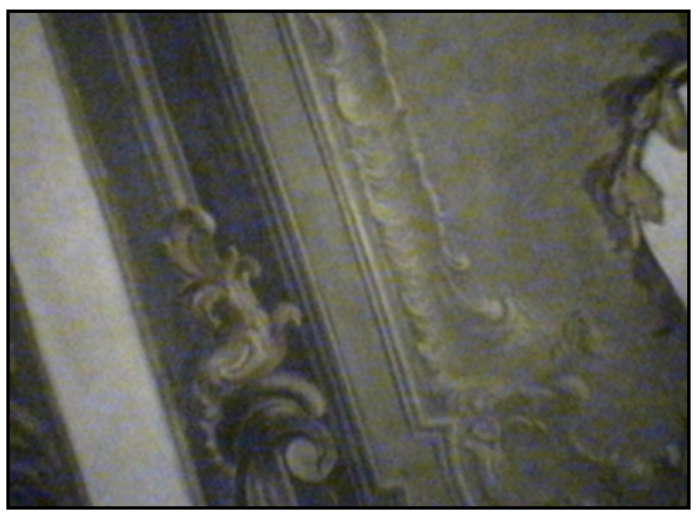

Fig. 1, Saint Maria in Strada, sec XVII, visual image of the ceiling

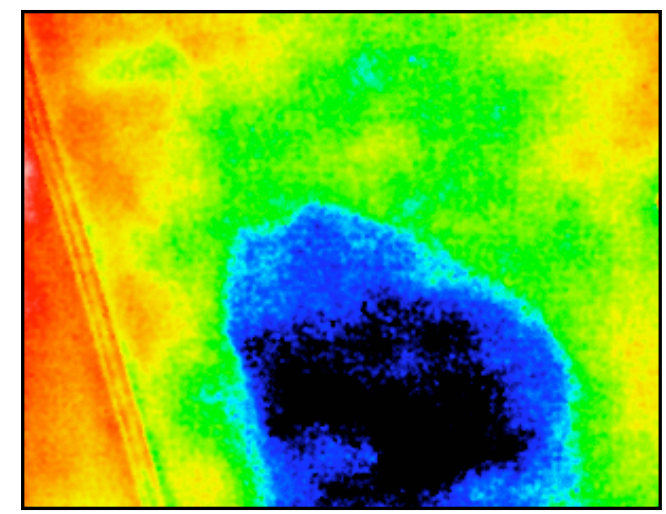

Fig. 2, IR Thermography of the same zone at transient condition

In several study cases IRT showed different plasters up (in fig. 2, IRT reveals a large patch of plaster, which was accurately covered by decoration). In some of them [3], physical-chemical analysis of samples allowed to exclude that the composition and granulometry of mortars could be differentiated between the mortars. Further assessment, at a very close distance from the surface, allows authors and restorers to assume that the kind of finishing could be responsible for the different heating distribution on the surface. The use of different tools implies a different compression of the operator's hand on wet mortar, that causes a different density of the most exterior layers, and a different roughness of the surface. Several thermographic sequences, recaptured at a rate of 10 and 60 seconds, served to obtain the heating curve of the surfaces. The final thermal gradient is some degrees, depending on the time of heating. 


\section{Materials e methods}

In the first step of the research, authors evaluated the affection of surface roughness on the heat absorption by irradiation, using a climatic room $\left(T_{\text {air }}=35^{\circ} \mathrm{C}\right.$, $\mathrm{RH}=50 \%$ ). The hypothesis about the key factors, which determines the observed different absorption curves of heating, required to reproduce the test in the laboratory. 24 bricks supported 12 different plasters, which were spread using four different tools (spatula, trowel, wooden float, sponge; plaster about 2-3 mm thickness). Among the samples, a mortar $\left(\mathrm{CaCO}_{3}\right.$, rich lime and sand) resulted differently responding to thermal stimulation, according to the different finishing. The thermographic sequences of the heating allowed to obtain the heating curve of small areas for each sample (fig. 3).

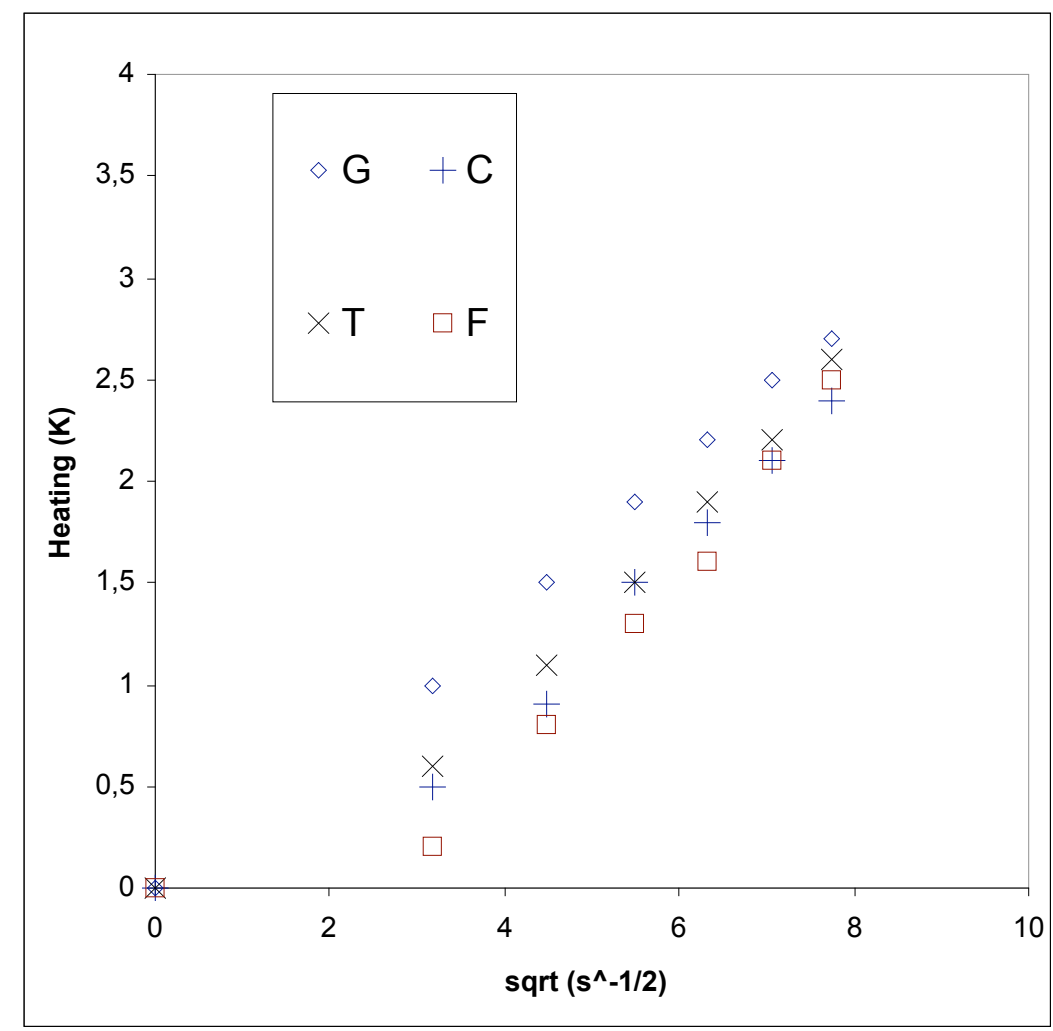

Fig. 3, graphic of the increase of temperature vs. time on mortar samples (heating by radiation); $T$ spatula, $G$ sponge, $F$ sponge float, $C$ trowel finishing

The trend is similar in each area, and it is possible to group together sponge float and spatula. This group' trend shows an intermediate heating between trowel and sponge. Sponge shows the higer heating from the beginning (70 seconds), probably due to a higher absorption of irradiation (average reflection about $40 \%$ in 
400-1100 $\mathrm{nm}$ range). Verification of the absorbance properties in the visible-NIR spectral band and emissivity at thermal IR (8-14 micron) confirmed the presented hypothesis.

The videomicroscopy (magnifying $100 \mathrm{x}$ ) confirmed the hypothesis: operators shot four images for each samples, choosing zones with similar texture and avoiding any defect of the surface. Moreover, a further image processing of these images allowed to calculate the area of the projection of the exposed sand grains over the plan which intersect the microscope focus, and which is parallel to the analysed surface. Because of the plan is kept equal for each image, the average area calculated for each image can be comparable. In this way, authors connected the roughness of the surface to a quantitative parameter, EGAA (Exposed Grains Average Area). The highest values of EGAA correspond to the roughest surface. The prominent presence of sand grains, determines the optical properties of the surface, and consequently the properties of irradiation balance of the surface, which directly affects the thermal behaviour of the sample surface.

As a conclusion, the comparison between thermal behaviour and localisation of mortar grains allows to evaluate how much the finishing techniques affect the thermal characteristics.

By testing mortar samples, authors noticed some factors affecting the results of absorption and evaporation tests (for example: mortar layers too thin, some delamination of mortar layer, affection of brick' water and vapour absorption on mortar absorption, latent heat of brick). For that, new samples and a new test procedure were performed in the second part of the research.

The researchers produced 72 new samples, with controlled ingredients and the same proportions (including the water) and geometry (about $9.5 \mathrm{~cm}$ diameter), mortar at whole thickness $(6 \mathrm{~mm})$, using 4 tools for finishing (spatula, sponge, wooden float, trowel). Mortars were put in plastic petris. The same operator used the tools for the finishing, at the same time after filling the small containers. Unfortunately, during the drying phase, many cracks broke the surface of various samples, and some of them were crossed in the whole thickness. This fact conditioned the choice of areas for IRT and hygroscopicity tests.

By eliminating bricks, operators eliminated thermal exchange factors between bricks and mortars; because of the same composition of mortars, authors considered any thermal anomaly (which was shown by active thermography) due to absorption anomalies of irradiation and heat propagation from exterior towards the interior layers of the material.

Experimental tests on samples are listed in the following:

1) Active IRT, heating by irradiation 2) Passive IRT, at evaporation condition 3) Evaporation flux by surface unity 4) Videomicroscopy on 3 areas for each sample (EGAA evaluation).

1) Heating was obtained by means of two halogen lamps, 500 Watt each, at 80 $\mathrm{cm}$ from the samples, symmetrically oriented towards the samples, at $40^{\circ}$. The samples were vertical, one by one in the same location in front of lamps and IR Thermography equipment, to avoid the irregularities of irradiation flux which were measured in the preliminary test. Recaptures at a rate of 10 sec., the sequence are 5 minutes long, at controlled bounder conditions. Operators performed a thermal analysis on small areas, obtaining the total heating absorption and the trend of absorption in the whole sequence. A further elaboration of the heating curve versus square root of time gave the curve of temperature increase. 
2) Passive recapture by IRT, at a rate of $10 \mathrm{sec}$, sequence two minutes long. During the recapture, a operator dropped a distillated water drop on the samples surface. The sequence shows the diffusion of the surface wetting versus the geometrical characteristics of the surface and its compactness.

3) Evaporation flux measures, by surface unity, allowed to quantitatively evaluate differences due to the surface characteristics of samples.

4) Results of videomicroscopy of three sound areas for each sample allowed the operators to measure the ratio between the surface of sand grains. The procedure was preliminarly tested on bricks and mortars samples. In these second series of mortar a major accuracy was required because of the higher smoothness and homogeneity of all the surfaces. Homogeneity was due to a thinner granulometry of sand, the use of plastic containers (with rigid edges), the diameter of petris (which is smaller than the dimension of tools side - trowel, spatula, float), the timing of finishing (while mortars began to carbonate).

\section{Results and discussion}

\subsection{Active IRT}

Graphic in fig. 5 shows the increase of temperature curves versus square root of time, and the linear interpolation of first 80 seconds of heating. Authors observed the temperature increase in the first 80 seconds because only the effects of heat transfer in the very exterior layers of surface (few $\mathrm{mm}$ ) are under analysis.

There are three types of heating, substantially different, corresponding to sponge, float and tools with a metallic blame (trowel and spatula).

The slowest heating corresponds to the sponge finishing, the fastest heating to float; metallic blade tools (trowel and spatula) have a midway behavior.

The lowest heating of the sponge finished sample is due to the preparation of sample: sponge allows a higher compression of surface (if compared with metallic blade-tools), because it is elastic and the operator's hand compression is not contrasted by the rigid container edges. This effect, although it is minimal, causes a major density of the exterior layers and therefore a major thermal inertia.

In the other samples, the rigid tools find a constraint reaction from the edges, which encumbers the operator's hand compression on the surface.

At the end, about the float showing the higher temperature increase, observation of the tools lead to a further note: even though it has a sponge surface for finishing the plaster, it has a rigid supporting structure (a thick plastic plan), which has a lower elasticity than metallic blades, so the compression of the operator hands can not be transferred to the surface at all, because of constraint of the edges of the containers.

\subsection{Passive IRT}

Fig. 6 clearly shows the differences of propagation of water in the dry samples. Geometry of the drops is very different according to the surface: on floated surface, the wet zone is a perfect circle, because of the effective diffusion of fluid in a material which has homogeneusly distributed microporoses; on the opposite side, spatula and trowel cause a similar porosity in the surface; here, the wet area has an irregular shape, because of macroporouses, which prevent a homogeneous diffusion of water and modify the geometric circle shape, typical of homogeneous diffusion. The assumed presence of macroporous could be caused by the mechanical action of 
abrasive metallic blades; the tools, both used at cut or flat position during the first phase of drying, remove the binder layer over the more prominent part of the sand grains. Surface finished with sponge shows a midway shape: the wet area is a circle, but the girth is irregular.

Table 1 , in the following, shows the calculated angular coefficient of the temperature decreasing during the evaporation of one drop of water over the four samples of plaster.

Table 1. Angular coefficients of temperature decreasing on the differente finishing surfaces

\begin{tabular}{|c|c|c|c|c|}
\hline Tools & (C) Trowel & Spatul & $\begin{array}{c}\text { Spong } \\
\text { e(G) }\end{array}$ & $t(F)^{\text {Floa }}$ \\
\hline \begin{tabular}{l}
\multicolumn{1}{c}{ Angular } \\
cofficient during \\
evaporation coooling
\end{tabular} & 0.0121 & $9 \quad 0.015$ & 0.0204 & 0.01 \\
\hline
\end{tabular}

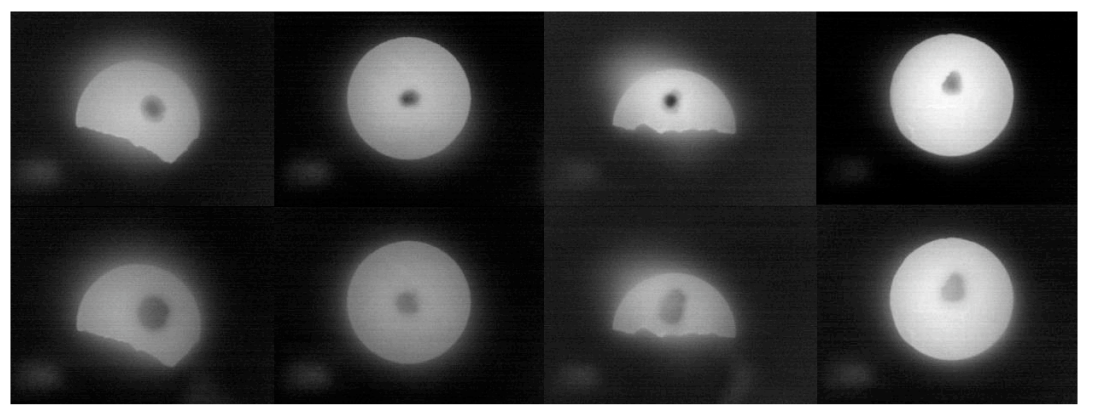

F

C

$\mathrm{T}$

$\mathrm{G}$

Fig. 6: Drops of water spreading in the four samples of plaster. At the beginning (top line) and after 90 seconds. In float finishing $(F)$, spreading is more regular than in the other three samples. IRT images, passive approach

$\left(R H=40 \%, T=20^{\circ} \mathrm{C}\right.$, temperature range 22.6-27.8; emissivity 0.85$)$

\subsection{Evaporation flux}

Fig. 7 shows the graphic of evaporation flux versus water content (as weight percentage). Different evaporation phases can be distinguished in the four surface finishings: sponge $(\mathrm{G})$, spatula $(\mathrm{T})$ and trowel $(\mathrm{C})$ finishing have higher values of evaporation flux, than float, and their values are constant at water content up to $10 \%$. Float finishing $(F)$ differs because it has an initial very high value of flux: in this phase most of water content evaporates; consequently, in a further step of the process, the evaporation flux value is lower than on the other finishing surfaces. As passive IRT verified, float finishing has a very different behavior from other finishing. 
http://dx.doi.org/10.21611/qirt.2006.092

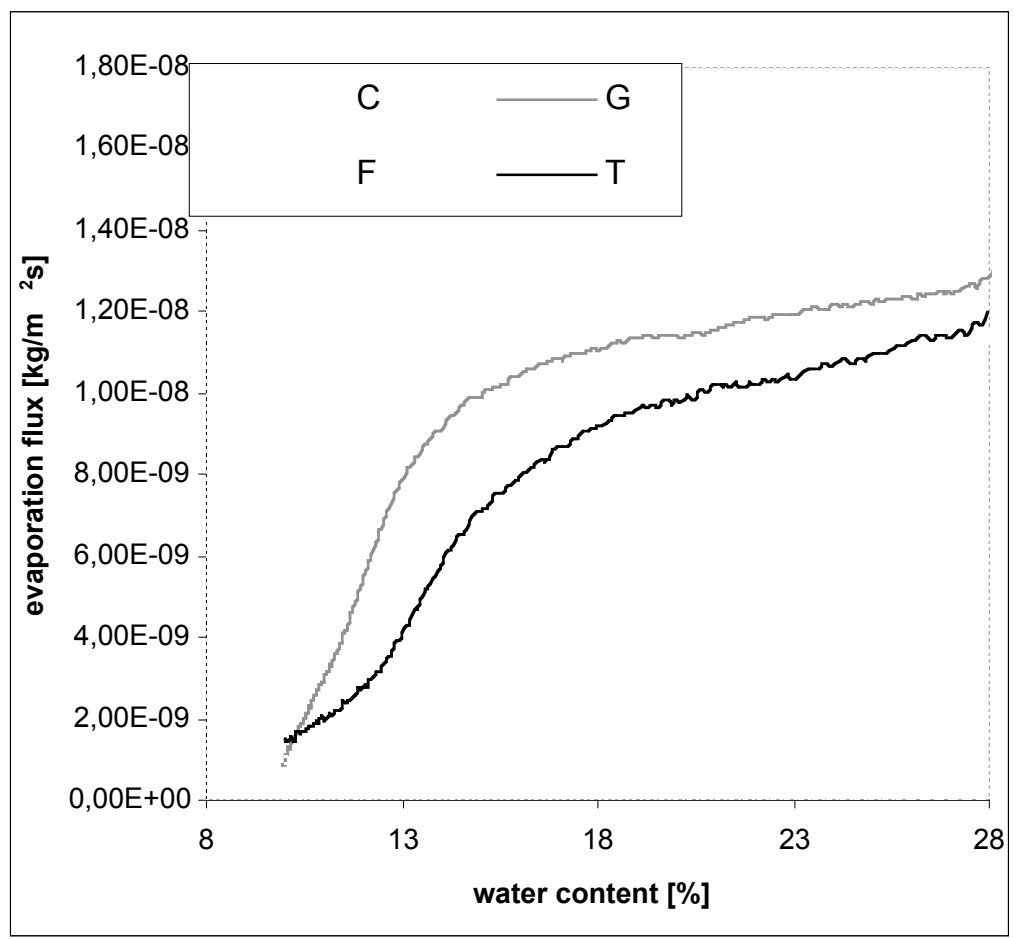

Fig 7: evaporation flux versus water content. Sponge $(G)$, spatula $(T)$ float $(F)$ and trowel (C). Evaporation at $45 \% \mathrm{RH}, 20^{\circ} \mathrm{C}$ temperature, in climatic room

\section{4}

\section{Videomicroscopy}

Fig. 8 shows very similar surfaces, although EGAA parameter is slightly different in each finishing. Homogeneity of surface allowed to exclude the affection of spectral absorbance on the IRT results. If plasters can be compared as irradiation absorbance, the presented IRT procedure is accurate for detecting difference of density of the very exterior layers of surface, that means granulometry, exposition and color of sand grains. In the presented test procedure, videomicrospcopy assets homogeneity of surface, and for that it is very useful for validation of IRT results.
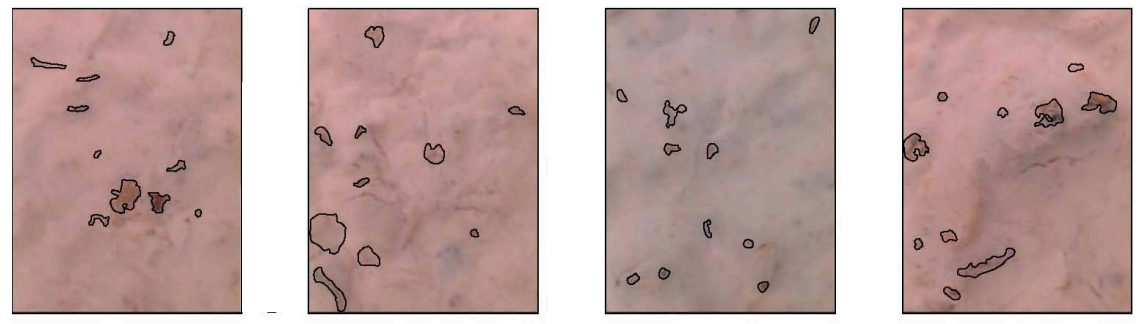
Fig. 8: from the left side: trowel, float, spatula, sponge finishing; calculation of EGAA for each sample

Table 2, in the following, shows the summary of research results.

Table 2. results synopsis

\begin{tabular}{|c|c|c|c|c|c|}
\hline Sampl & $\begin{array}{c}\text { Mean } \\
\text { reflection in } \\
400-1100 \\
\mathrm{~nm} \text { range }\end{array}$ & $\begin{array}{c}\text { Angular } \\
\text { coefficient } \\
\text { during } \\
\text { evaporation } \\
\text { test }(\mathrm{K} / \mathrm{s})\end{array}$ & $\begin{array}{l}\text { Evaporati } \\
\text { on flux }\end{array}$ & $\mathrm{AA}^{\mathrm{EG}}$ & $\begin{array}{c}\text { Angular } \\
\text { coefficient } \\
\text { during } \\
\text { evaporation test } \\
\left(\mathrm{K} / \mathrm{s}^{-1 / 2}\right) \\
\text { (thermal } \\
\text { effusivity) }\end{array}$ \\
\hline $\begin{array}{r}F \\
\text { (float) }\end{array}$ & $59 \%$ & 0.157 & regular & $9^{0.2}$ & 0.332 \\
\hline $\begin{array}{c}\mathrm{G} \\
\text { (sponge) }\end{array}$ & $55 \%$ & $\begin{array}{c}0.204 \\
\text { (highest) }\end{array}$ & $\begin{array}{l}\text { Regular } \\
\text { (highest) }\end{array}$ & $1^{0.3}$ & $\begin{array}{c}0.355 \\
\text { (highest) }\end{array}$ \\
\hline $\begin{array}{c}\mathrm{T} \\
\text { (spatula) }\end{array}$ & $60 \%$ & 0.159 & regular & $1^{0.1}$ & 0.337 \\
\hline $\begin{array}{c}\mathrm{C} \\
\text { (trowel) }\end{array}$ & $58 \%$ & $\begin{array}{c}0.121 \\
\text { (lower) }\end{array}$ & $\begin{array}{l}\text { different } \\
\text { (lower) }\end{array}$ & $4^{0.1}$ & $\begin{array}{c}0.321 \\
\text { (lower) }\end{array}$ \\
\hline
\end{tabular}

EGAA seems to do not affect both evaporation and heating of the samples, during the active IRT. In active IRT, cooling has a good correlation with evaporation rate, and the drop spreading, and, therefore, with the microporosity of the most exterior layers of the surface.

Active IRT results fit with the above exposed one, even though variations of the surface reflectance almost prevent a precise evaluation of differences of materials thermal behaviour.

\section{Conclusions}

Thermography methods are able to measure variation of the structure of the surface, due to different finishing: active and passive IRT allow to pinpoint different factors.

Active termography shows that, at even condition of the material, a strict procedure for heating increase measurent (by even irradiation, that means controlling the quantity of heating $Q$ ), allows to distinguish the differences of density of the exterior layers of the surface, which are due to finishing.

Passive thermography pinpoints the difference of thermal behavior regarding surface evaporation, therefore the microporous structure of the materials. Research results allow to evaluate density of the exterior layer throughout a measurement of thermal effusivity, and to distinguish its affection on the parameters for detecting different plaster finishing. The procedure confirms that IRT is one of the most appropriate technique for surface documentation. 
Presented procedure is not feasible in the field, because of well known difficulties, nevertheless it constitutes a test for assessment of the surfaces. Results are very useful for documentation before restoration project, and for controlling the intervention.

\section{REFERENCES}

[1] S. Della Torre, E. Rosina, S. D’Ascola and S. Caglio, Restauri a rischio, microclima e differenze superficiali dei materiali in opera, 11 Conferenza Nazionale PND, Milano (2005).

[2] S. Della Torre, E. Rosina, M. Catalano, C. Faliva, G. Suardi, A Sansonettiand L. Toniolo, Early Detection and Monitoring Procedures by Means of Multispectral Image Analysis, Art 2005, Lecce (2005).

[3] S. Della Torre, E. Rosina, V. Pracchi, G. Suardi, N. Ludwig, V. Redaelli, A. Sansonetti and R. Negrotti, Le indagini multispettrali per il riconoscimento telemetrico degli interventi di restauro nelle pitture murali, in atti del XXI Convegno Internazionale, Bressanone (2005) 907-913. 